\title{
Sarah T. Pendlebury, Matthew F. Giles, Peter M. Rothwell: Transient Ischemic Attack and Stroke: Diagnosis, Investigation and Management
}

\author{
Cambridge University Press 2009, paperback, £38, US \$70, ISBN 9780521735124
}

\section{Antonio Carolei}

Published online: 15 April 2009

(C) Springer-Verlag 2009

Stroke is the most common neurological disorder, affecting millions of people worldwide each year, and its burden is likely to increase with aging of the population. Many changes have occurred over recent decades in the diagnosis and treatment of patients with either transient ischemic attack (TIA) or stroke and, at the moment therapeutic advances are coming at a rapid pace together with the implementation of new organizational models of care. Research has shown that accurate diagnosis and urgent treatment in selected cases can reduce the risk of stroke recurrence after a TIA or a minor stroke by up to $80 \%$. The consequence is the need for continual education and updating even for physicians who are not involved in vascular neurology.

This book by Peter Rothwell and co-workers begins with a remarkable foreword by Charles Warlow, the mentor of this leading group on cerebrovascular diseases. Transient Ischemic Attack and Stroke represents an excellent manual which has the coherence of a single-author book due to the experience of and harmony among the three authors.

The book which focuses on the diagnosis and management of TIA, minor and major stroke, also covers vascular dementia in terms of specific events, and is organized into six different sections dealing with the main current topics.

As might be expected, all the major areas of interest are represented, and the level of detail in each of the 32 chapters is at least as great as that in other leading textbooks on the same subject. In general, each chapter of the book is comprehensive and up to date and contains pertinent and recent references. Several chapters, most notably those on therapy, are among the best I have seen. Particularly well-framed and updated is Chapter 18 , dedicated to methods of assessing treatments and how to apply their results to the individual patient.

Topics that might otherwise confuse the general practitioner and the trainee, such as when to perform any type of carotid intervention in symptomatic and asymptomatic patients, are allocated entire chapters with annexed tables and charts, explaining in detail not only which subgroups benefit most but also, especially useful in clinical practice, which individuals benefit most.

Transient Ischemic Attack and Stroke would be a fine addition to the library of neurologists and to that of any physicians working in areas of practice related to stroke, e.g. internists, geriatricians, neuroradiologists, neurosurgeons, vascular surgeons, and also nurse practitioners. In this remarkably comprehensive guide, three of the leading experts in the field directly explain how to approach a certain problem, how to make a choice, and why that choice leads to success in everyday practice.

\footnotetext{
A. Carolei $(\bowtie)$

Department of Neurology, Regional Headache Referral Center,

University of L'Aquila, Piazzale Salvatore Tommasi 1,

67010 L'Aquila, Italy

e-mail: a_carolei@yahoo.com
} 